\title{
Design of a highly active Pd Catalyst with P,N Hemilabile Ligands for alkoxycarbonylation of alkynes and allenes: a density functional theory study
}

\author{
Shahbaz Ahmad ${ }^{[a]}$ and Michael Bühl ${ }^{*[a]}$
}

\begin{abstract}
In palladium-catalysed methoxycarbonylation of technical propyne, the presence of propadiene poisons the hemilabile $\operatorname{Pd}(P, N)$ catalyst. According to density functional theory calculations (B3PW91-D3/PCM level), a highly stable m-allyl intermediate is the reason for this catalyst poisoning. Predicted regioselectivities suggest that at least $11 \%$ of propadiene should yield this allyl intermediate, where the reaction gets stalled under the turnover conditions due to an insurmountable methanolysis barrier of $25.8 \mathrm{kcal} \mathrm{mol}^{-1}$. Results obtained for different ligands and substrates are consistent with the available experimental data. A new ligand, (6-Cl-3-Me-Py) $\mathrm{PPh}_{2}$, is proposed, which is predicted to efficiently control the branched/linear selectivity, avoiding rapid poisoning (with only $0.2 \%$ of propadiene being trapped as $\mathrm{Pd}$ allyl complex), and to tremendously increase the catalytic activity by decreasing the overall barrier to $9.1 \mathrm{kcal} \mathrm{mol}^{-1}$.
\end{abstract}

The use of sustainable and abundant resources in regioselective direct synthesis of fine chemicals is highly desirable. Design of commercially cheap catalysts with high turnover number at optimal reaction conditions is a key challenge in this area. The other challenges are the isolation procedures, broad substrate scope and high atom-economy. Homogeneously catalysed carbonylation reactions using transition metal catalysts are important industry processes. ${ }^{[1]}$ Carbonylation reactions allow for easy expansion of the carbon chains along with installation of chemo- and regioselectivity. ${ }^{[1 c, 2]}$

Alkoxycarbonylation (hydroesterifications) of alkynes represents a straightforward metal catalysed production of acrylate esters with $100 \%$ atom economy. ${ }^{[3]}$ Methyl methacrylate $(\mathrm{MMA})^{[3 \mathrm{a}, 3 \mathrm{~b}, 4]}$ is the product of methoxycarbonylation of propyne. MMA is a small molecule feedstock, crucial in modern chemical industry due to its polymer poly(methyl methacrylate). ${ }^{[5]}$ Poly(methyl methacrylate) is also known as Perspex (trade name) and in high demand by industry in the formation of liquid-crystal display screens, and in touch screen electronics. ${ }^{[6]}$

At industrial scale, production of MMA is a two-step process, comprising (i) alkoxycarbonylation of ethene at a homogeneous
Pd catalyst with an $\alpha, \alpha^{\prime}$-bis-[di-tert-butylphosphino]-o-xylene ligand yielding methyl propionate, followed by (ii) a heterogeneous conversion to MMA. ${ }^{[5,7]}$

Hemilabile $\mathrm{Pd}(\mathrm{P}, \mathrm{N})$-type ligands are of considerable interest in homogeneous catalysis due to their widely variable coordination modes. Homogenous methoxycarbonylation of propyne using a hemilabile $\mathrm{Pd}(\mathrm{P}, \mathrm{N})$ catalyst at low $\mathrm{pH}$ conditions is another route for direct MMA synthesis (Drent system, Scheme 1). ${ }^{[3 a-d, 8]}$ This reaction appeared very attractive as it produced almost exclusively the desired branched stereoisomer (MMA), and only traces of the linear product (methyl coronate). Increasing the bulk at pyridyl moiety $\left(R_{1}\right.$ in Scheme 1$)$ further increased the preference for MMA.

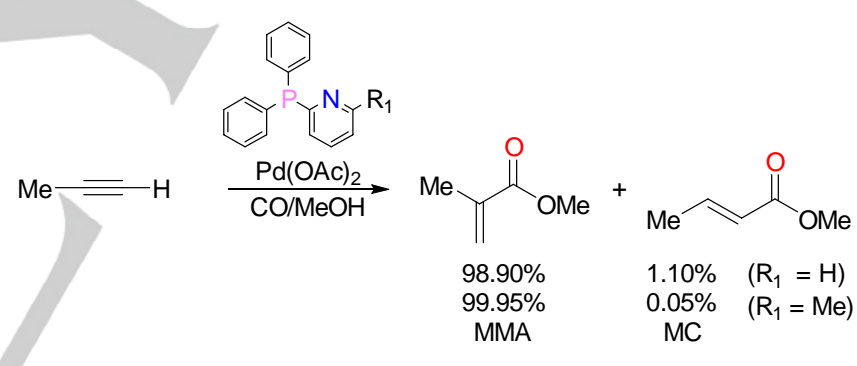

Scheme 1

We recently applied state-of-the-art density functional theory (DFT) studies to disclose the mechanistic details of homogenous methoxycarbonylation of propyne using hemilabile $\operatorname{Pd}(\mathrm{P}, \mathrm{N})$ catalyst. $^{[8 b, 8 c, 9]}$ Our mechanism involves proton shuffling by the pyridyl groups in the initiation and termination steps. The dangling pyridyl moiety can act as in situ base, protonating coordinated propyne followed by thermodynamically favoured $\mathrm{CO}$ insertion and then deprotonating methanol with instantaneous ester formation. The steps involved in our proposed mechanism (denoted pathway E) are illustrated in Scheme 2.

[a] S. Ahmad, Prof. Dr. M. Bühl

EastCHEM School of Chemistry, University of St. Andrews,

North Haugh, St. Andrews, Fife KY16 9ST, United Kingdom.

Email: buehl@st-andrews.ac.uk

Supporting information for this article is given via a link at the end of the document. 


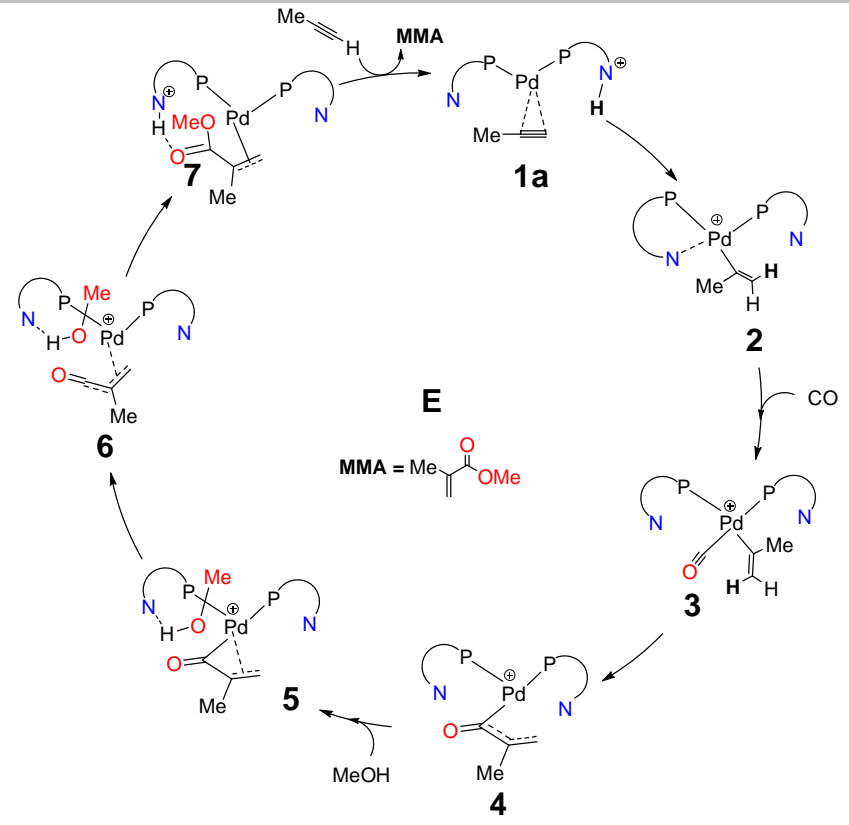

Scheme 2. Proposed mechanism (pathway E) for methoxycarbonylation of propyne. ${ }^{[9]}$

This single step MMA synthesis seems to be very attractive with $100 \%$ atom-economy. However, propyne from industrial waste contains large proportions of propadiene which poisons the catalyst. Propadiene would have to be purified which makes the system uneconomical and therefore methoxycarbonylation has not yet been developed into an industrial process. ${ }^{[3 \mathrm{~b}-\mathrm{d}]} \mathrm{A}$ clever catalyst design by tuning of stereo-electronic properties of the ligand and the metal centre could supress the catalyst poisoning by olefins, which would make this system economically interesting. ${ }^{[10]}$

We have now uncovered a potential reason for the poisoning of the Drent catalyst by propadiene. Like propyne, propadiene association to the metal gives two type of complexes, one, $\mathbf{9}^{+}$, that leads to the desired branched product (MMA) and one, $9 \mathrm{~L}^{+}$, that may lead to the linear product (see Figure 1). ${ }^{[11]}$ Both complexes are interconvertible under the turnover conditions $\left(\Delta \mathrm{G}_{9}{ }^{+} \rightarrow 9 \mathrm{~L}^{+}=-0.7\right.$ kcal mol ${ }^{-1}$ and $\left.\Delta \mathrm{G}^{\ddagger}{ }_{9}{ }^{+} \rightarrow 9 \mathrm{~L}^{+}=8.8 \mathrm{kcal} \mathrm{mol}^{-1}\right)$. In $9^{+}$, proton transfer to the terminal carbon of propadiene gives an agostic intermediate $\mathbf{2} \mathbf{i}^{+}$, which is an isomer of $\mathbf{2 i}^{+}{ }^{+{ }^{[9]}} \mathbf{2} \mathbf{i}^{+}$rearranges into $\mathbf{2}$ (Figure 2), which then follows the same steps as in mechanism $E$ to give the final branched product, MMA (Scheme 2). On this pathway, which is just a variety of pathway $\mathrm{E}$, there is thus no evidence for catalyst poisoning by propadiene.

On the other hand, proton transfer to the central carbon of propadiene in $9 \mathrm{~L}^{+}$gives rise to a very stable allylic complex $10 \mathrm{~L}^{+}$

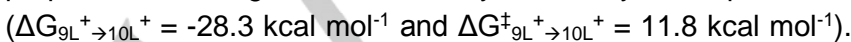
We have traced the complete cycle starting from this intermediate to the methyl crotonate product, regenerating $9 \mathrm{~L}^{+}$(denoted pathway $\mathbf{F}$, see Scheme 3, Figure S1, and Figure S2 in the supporting information ( $\mathrm{SI}$ ) for details).

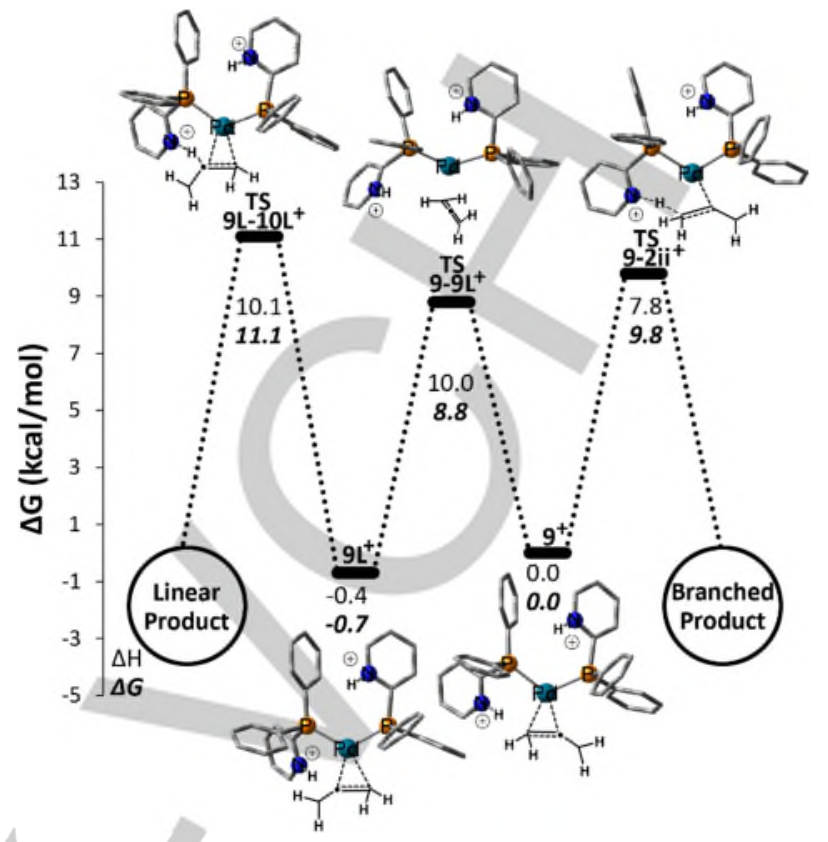

Figure 1. Pathways for formation of branched (right) and linear (left) products; energies $(\Delta \mathrm{H}$ and $\Delta G)$ are in $\mathrm{kcal} \mathrm{mol}^{-1}$ relative to $9^{+}$. Selectivity is governed by the difference of free energies between TS9-2ii+ and TS9L-10L+.

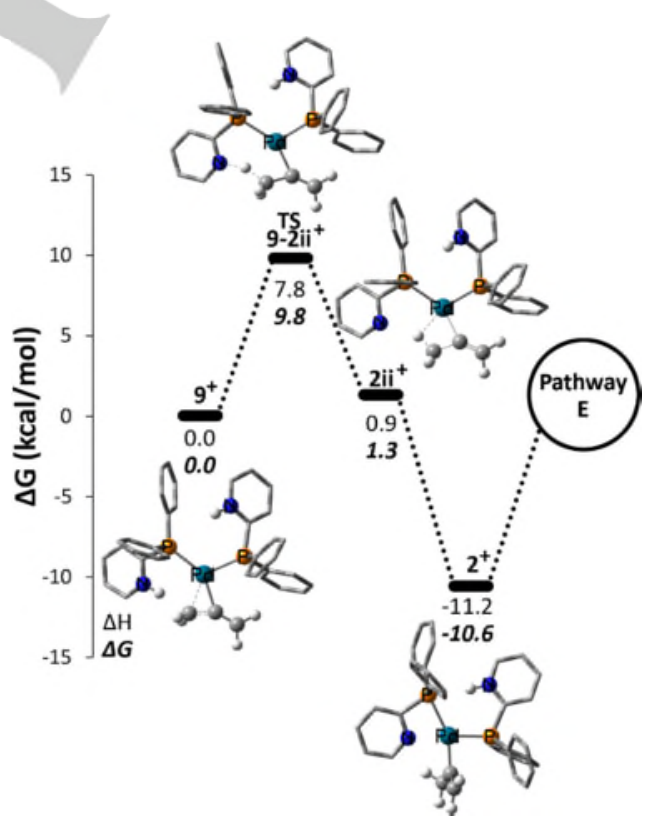

Figure 2. Methoxycarbonylation of propadiene following pathway E. Energies $\left(\Delta H\right.$ and $\Delta G$ ) in kcal mol${ }^{-1}$ relative to $9^{+}$.

On this pathway, $10 \mathrm{~L}^{+}$and the transition state of methanolysis step, TS14L-8+, are, respectively, the most abundants reaction intermediate (MARI) and the highest energy transition state (HETS, according to Shaik's energy span mode ${ }^{[12]}$ ). The resulting overall barrier is $25.8 \mathrm{kcal} \mathrm{mol}^{-1}$ (energy difference between the MARI and the HETS including BSSE corrections, cf. Table S3) 
corresponding to a turnover frequency (TOF) of $1.26 \times 10^{-5} \mathrm{~h}^{-1}$ at $45{ }^{\circ} \mathrm{C}$. Such a very low TOF under the reaction conditions suggests that the reaction will stall at the MARI (10L+ in Scheme 3 ), poisoning that fraction of the catalyst that has followed this pathway from the initial propadiene uptake. The linear/branched selectivity illustrated in Figure 1 therefore does not determine the regiochemistry of the product, but whether or not the catalyst can be regenerated for the next turnover. We have identified TS9-2ii ${ }^{+}$ and $\mathbf{T S} \mathbf{9 L}-\mathbf{1 0 L}+$ as selectivity determining transition states with a $\Delta \Delta G^{\ddagger}=1.3 \mathrm{kcal} \mathrm{mol}^{-1}$. This corresponds to a selectivity of $11 \%$ towards the linear product (or rather, the allyl-poisoned catalyst) at $45^{\circ} \mathrm{C}$ (Figure 1). Technical propyne contains variable amounts of propadiene as impurity. If, during each turnover, this impurity ${ }^{[13]}$ can effectively remove $11 \%$ of the catalyst from the reaction mixture, it should indeed lead to rapid catalyst poisoning.

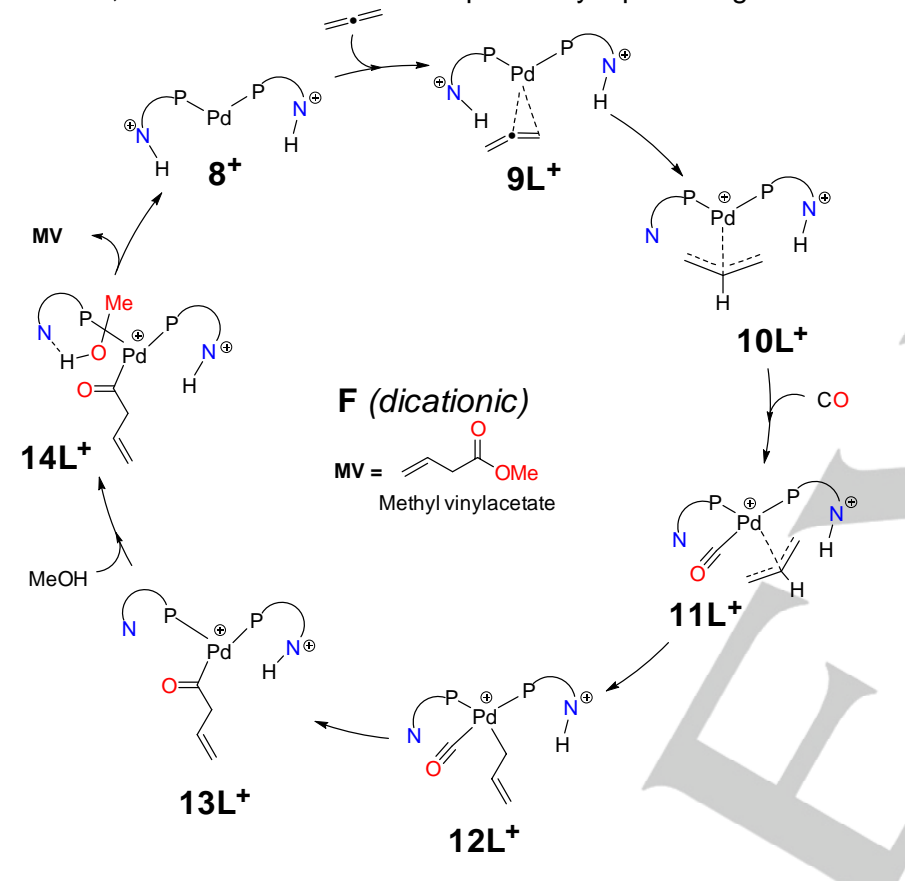

Scheme 3. Pathway F: catalytic cycle for the dicationic version according to DFT. [11]

We note that, using the same catalyst with slightly different substrates (phenylallene and butanol), Beller and co-workers did not report catalyst poisoning, but could obtain alkoxycarbonylation products. However, they obtained only low yields (39\%) after 20 hours of reaction time at $110{ }^{\circ} \mathrm{C} .{ }^{[14]}$ Under these conditions, even the high overall barrier on pathway $\mathrm{F}$ could be overcome. Therefore, our findings are consistent with Beller's results (see Figure S11 in the SI)

Based on our results, we can now hypothesise how to design Drent catalysts that are less prone to propadiene poisoning. To achieve this, all that is required should be to increase the branched selectivity with the propadiene substrate (or rather to suppress the formation of any linear product, see Scheme 4), which is the desired reaction anyway. For propyne as substrate, branched selectivity increases with the bulk at position 6 of the pyridyl moiety., ${ }^{[3 a-c, ~ 8 b, ~ 8 c] ~}$

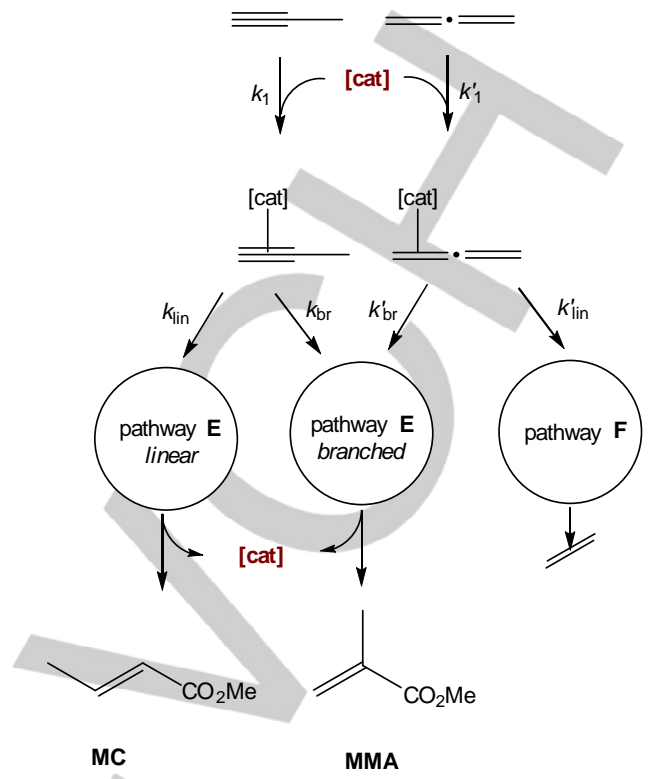

Scheme 4. Proposed basis for ligand design: improved tolerance of the catalyst toward propadiene is expected if entry into pathway $F$ is blocked, i.e., if the ratio of $k_{b r}^{\prime} / k^{\prime}$ lin is maximised.

An electron withdrawing group at the same position helps towards this desired selectivity and also increases the reaction rate. ${ }^{[9]}$ We have thus evaluated the effect of chloro and methyl substituents at 6-position of the 2-pyridyl moiety on the selectivity with propadiene as substrate. (6-Cl-Py)PPh ${ }_{2}$ ligand increases $\Delta \Delta \mathrm{G}^{\ddagger}$ between TS9-2ii and TS9L-10L+ (Figure 1) from $1.3 \mathrm{kcal} \mathrm{mol}^{-1}$ to $3.6 \mathrm{kcal} \mathrm{mol}^{-1}$, corresponding to a selectivity of $>99 \%$ towards the branched product. In contrast, (6-Me-Py) $\mathrm{PPh}_{2}$ decreases $\Delta \Delta \mathrm{G}^{\ddagger}$ from $1.3 \mathrm{kcal} \mathrm{mol}^{-1}$ to $1.1 \mathrm{kcal} \mathrm{mol}^{-1}$. Both predictions correspond to the results obtained at Shell[15] that (6-Cl-Py) $\mathrm{PPh}_{2}$ is more tolerant, whereas (6-Me-Py)PPh is slightly less tolerant towards propadiene than the parent $\mathrm{PyPPh}_{2}$ ligand system.
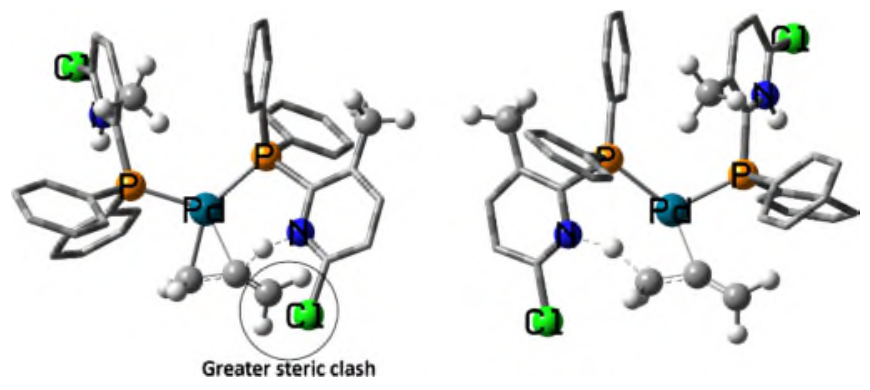

Figure 3. Enhanced steric clash in TS9-10L+ (left) gives greater tolerance towards allene poisoning.

We found previously that in the $\left(4-\mathrm{Me}_{2} \mathrm{~N}-\mathrm{Py}\right) \mathrm{PPh}_{2}$ ligand, the $\mathrm{Me}_{2} \mathrm{~N}$ substituent at the para position increases the basicity of pyridyl moiety, which makes protonation of propyne more 
difficult. ${ }^{[0]}$ To make $\mathbf{8}^{+}$as a stable intermediate with minimal effects on the proton transfer step, we have considered another ligand system, (6-Cl-3-Me-Py) $\mathrm{PPh}_{2}$. Presence of both 6-Cl and 3Me substituents provides steric clashes in such a way (Figure 3)

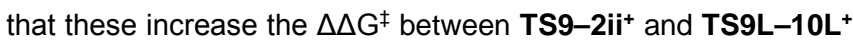
from $1.3 \mathrm{kcal} \mathrm{mol}^{-1}$ to $4.0 \mathrm{kcal} \mathrm{mol}^{-1}$. This would mean that at $45^{\circ} \mathrm{C}$, only $0.2 \%$ of propadiene would be diverted into the linear (poisoning) pathway F. Depending on the amount of propadiene present as impurity, this should lead to respectable turnover numbers (see SI for an estimate).

In the reaction with propyne, a selectivity for branched MMA of $>99 \%$ is predicted with this ligand, what is more, this ligand is predicted to decrease the overall barrier for MMA production in pathway $\mathrm{E}$ from $16.8 \mathrm{kcal} \mathrm{mol}^{-1}$ to $9.1 \mathrm{kcal} \mathrm{mol}^{-1}$. This barrier is even lower than that of the proton transfer step in $\mathbf{1 L}^{+}$(leading to the linear product with propyne, $10 \mathrm{kcal} \mathrm{mol}^{-1}$ with this ligand). Thus, formation of the linear product should be further minimised. Based on these results, the (6-Cl-3-Me-Py) $\mathrm{PPh}_{2}$ ligand should afford a much better catalyst than the known (6-Cl-Py) $\mathrm{PPh}_{2}$ ligand. In particular, the predicted overall barrier of $9.1 \mathrm{kcal} \mathrm{mol}^{-1}$ should make it the best catalyst for methoxycarbonylation of propyne/propadiene mixtures (and in general for alkoxycarbonylation of alkynes and allenes).

In conclusion, through DFT computations we have identified a possible reason for the poisoning of the original Drent catalyst with propadiene. One of the reaction channels accessible with that substrate (the one that would lead to the linear product), contains a deep thermodynamic sink in form of a m-allyl palladium complex. Conversion of this intermediate to the product (and closure of the cycle) is indicated to require a high barrier (via methanolysis), which is unsurmountable under the mild reaction conditions. All the results discussed above (and in the SI) for different ligands are compatible with the available experimental data. We also have designed a new ligand system for methoxycarbonylation of propyne, namely (6-Cl-3-Me-Py) $\mathrm{PPh}_{2}$, which is predicted to be more tolerant towards the presence of propadiene and should be highly efficient for alkoxycarbonylation of alkynes and allenes.

\section{Experimental Section}

Free energy and enthalpic corrections from the fully optimised geometries are carried out by computing harmonic frequencies analytically at 298.15 $\mathrm{K}$ on B3PW91 ${ }^{[16]} / \mathrm{SDD}(\mathrm{Pd}) / 6-31 \mathrm{G}^{\star *}(\mathrm{ECP} 1)$ level. Energies were refined at B3PW91-D3 ${ }^{[17]} / \mathrm{SDD}(\mathrm{Pd}) / 6-311+\mathrm{G}^{* *} / \mathrm{PCM}^{[18]}(\mathrm{MeOH})$ level. Full computational details are given in the $\mathrm{SI}$.

\section{Acknowledgements}

We thank EaStCHEM and the School of Chemistry for support. Computations were carried out on a local Opteron PC cluster maintained by Dr. H. Früchtl. We thank Prof. R. P. Tooze (Drochaid Research Services) for valuable discussions. For research data supporting this publication see DOI: XXXX. ${ }^{[19]}$
Keywords: homogeneous catalysis - DFT computations - reaction mechanisms - rational ligand design

[1] a) B. Cornils, W. A. Herrmann, M. Beller, R. Paciello, Applied Homogeneous Catalysis with Organometallic Compounds: $A$ Comprehensive Handbook in Four Volumes, Wiley-VCH Verlag GmbH Co. KGaA, Germany, 2003; b) M. Beller, Editor, Catalytic Carbonylation Reactions. [Inn: Top. Organomet. Chem.; 2006, 18], Springer GmbH, 2006; c) L. Kollar, Editor, Modern Carbonylation Methods, Wiley-VCH Verlag GmbH Co. KGaA, 2008; d) S. S. Stahl, J. Am. Chem. Soc. 2010, 132, 8524-8525; e) X.-F. Wu, H. Neumann, M. Beller, Chem. Rev. (Washington, DC, U. S.) 2013, 113, 1-35.

[2] X.-F. Wu, H. Neumann, M. Beller, Chem. Soc. Rev. 2011, 40, 49865009 .

[3] a) E. Drent, P. Arnoldy, P. H. M. Budzelaar, J. Organomet. Chem. 1993, 455, 247-253; b) E. Drent, P. Arnoldy, P. H. M. Budzelaar, J. Organomet. Chem. 1994, 475, 57-63; c) A. Dervis, P. G. Edwards, P. D. Newman, R. P. Tooze, S. J. Colesa, M. B. Hursthouse, J. Chem. Soc., Dalton Trans. 1999, 1113-1119; d) A. Dervisi, P. G. Edwards, P. D. Newman, R. P. Tooze, Dalton 2000, 523-528; e) A. Scrivanti, V. Beghetto, E. Campagna, M. Zanato, U. Matteoli, Organometallics 1998, 17, 630-635; f) A. Scrivanti, M. Bertoldini, V. Beghetto, U. Matteoli, A. Venzo, J. Organomet. Chem. 2008, 694, 131-136; g) C. S. Consorti, G. Ebeling, J. Dupont, Tetrahedron Lett. 2002, 43, 753-755; h) G. Kiss, Chem. Rev. (Washington, D. C.) 2001, 101, 3435-3456.

[4] a) Shell (E. Drent, D. H. L. Pello), Patent no. WO 95/03269A1, 1995 b) Shell (P. Arnoldy, A. P. M. Kremers), Patent no. EP 56/5199A2, 1993; c) F. Niele, Chem. Mag. (Rijswijk, Neth.) 1995, 12; d) J. Keijsper, P. Arnoldy, M. J. Doyle, E. Drent, Recl. Trav. Chim. PaysBas 1996, 115, 248-255; e) J. Andrieu, B. R. Steele, C. G. Screttas, C. J. Cardin, J. Fornies, Organometallics 1998, 17, 839-845; f) B. A Trofimov, R. N. Kudyakova, A. G. Mal'kina, V. V. Nosyreva, N. A. Kalinina, A. I. Albanov, Dokl. Akad. Nauk 2001, 378, 61-63; g) A. G. Mal'kina, R. N. Kudyakova, V. V. Nosyreva, A. V. Afonin, B. A. Trofimov, Russ. J. Org. Chem. 2002, 38, 1088-1092.

[5] B. Harris, Ingenia 2010, 18-23.

[6] M. Moukwa, in Chem. World, 2010, pp. 50-52.

[7] a) W. Clegg, G. R. Eastham, M. R. J. Elsegood, B. T. Heaton, J. A Iggo, R. P. Tooze, R. Whyman, S. Zacchini, Organometallics 2002, 21, 1832-1840; b) W. Clegg, M. R. J. Elsegood, G. R. Eastham, R. P. Tooze, X. L. Wang, K. Whiston, Chem. Commun. (Cambridge) 1999, 1877-1878; c) G. R. Eastham, R. P. Tooze, M. Kilner, D. F. Foster, D. J. Cole-Hamilton, J. Chem. Soc., Dalton Trans. 2002, 1613-1617; d) E. Zuidema, C. Bo, P. W. N. M. Van Leeuwen, J. Am. Chem. Soc. 2007, 129, 3989-4000.

[8] a) A. Dervisi, P. G. Edwards, P. D. Newman, R. P. Tooze, S. J. Coles, M. B. Hursthouse, J. Chem. Soc., Dalton Trans. 1998, 3771 3776; b) L. Crawford, D. J. Cole-Hamilton, E. Drent, M. Bühl, Chem. - Eur. J. 2014, 20, 13923-13926; c) L. Crawford, D. J. Cole-Hamilton, M. Bühl, Organometallics 2015, 34, 438-449.

[9] S. Ahmad, A. Lockett, T. A. Shuttleworth, A. M. Miles-Hobbs, P. G. Pringle, M. Bühl, Physical Chemistry Chemical Physics 2019, 21, 8543-8552.

[10] H. Adams, N. A. Bailey, J. T. Gauntlett, I. M. Harkin, M. J. Winter, S. Woodward, J. Chem. Soc., Dalton Trans. 1991, 1117-1128.

[11] Labels with superscript plus signs denote the dicationic version of the pathway, where both py moieties are initially protonated (which should be representative for the experimental conditions at low $\mathrm{pH}$ ). As the dicationic version of pathway $E$ gives selectivities better comparable to the experimental observations (see reference [9]), we will discuss the dicationic variant of mechanism $\mathrm{F}$ in this paper (for results for the monocationic variant see $\mathrm{SI}$ ). Our key conclusions are not affected by this choice.

[12] a) S. Kozuch, S. E. Lee, S. Shaik, Organometallics 2009, 28, 1303 1308; b) S. Kozuch, S. Shaik, Acc. Chem. Res. 2011, 44, 101-110. Propadiene gives a more stable complex, $9 \mathrm{~L}+$, than propyne $\left(1^{+}+\right.$

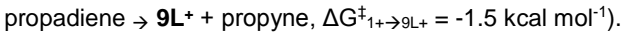

J. Liu, Q. Liu, R. Franke, R. Jackstell, M. Beller, J. Am. Chem. Soc. 2015, 137, 8556-8563.

a) A. D. Becke, J. Chem. Phys. 1996, 54, 1040-1046; b) J. P. Perdew, K. Burke, Y. Wang, Phys. Rev. B: Condens. Matter 1996 54, 16533-16539; c) J. P. Perdew, J. A. Chevary, S. H. Vosko, K. A. Jackson, M. R. Pederson, D. J. Singh, C. Fiolhais, Phys. Rev. B: Condens. Matter 1992, 46, 6671-6687.

[16] Shell (E. Drent, W. W. Jager, J. C. L. J. Suykerbuyk), Patent no. WO 95/05357, 1995.

[17] a) S. Grimme, J. Antony, S. Ehrlich, H. Krieg, J. Chem. Phys. 2010, 132, 154104/154101-154104/154119; b) S. Grimme, S. Ehrlich, L. Goerigk, J. Comput. Chem. 2011, 32, 1456-1465; c) T. Risthaus, S. Grimme, J. Chem. Theory Comput. 2013, 9, 1580-1591. 
WILEY-VCH

COMMUNICATION

[18] a) J. Tomasi, B. Mennucci, E. Cances, J. Mol Struct: THEOCHEM

1999, 464, 211-226; b) J. Tomasi, B. Mennucci, R. Cammi, Chem.

Rev. (Washington, DC, U. S.) 2005, 105, 2999-3093; c) A. Klamt, B. Mennucci, J. Tomasi, V. Barone, C. Curutchet, M. Orozco, F. J. Luque, Acc. Chem. Res. 2009, 42, 489-492.

[19] S. Ahmad, M. Bühl, Design of a highly active Pd Catalyst with P,N Hemilabile Ligands for alkoxycarbonylation of alkynes and allenes: a density functional theory study (Dataset), University of St Andrews Research Portal. 2019. https://doi.org/XXXX 
Entry for the Table of Contents (Please choose one layout)

Layout 1:

\section{COMMUNICATION}

Mechanistic insights from DFT calculations suggest new ways how to avoid poisoning of a $\mathrm{Pd}$ catalyst for MMA production by allene.
Shahbaz Ahmad, Michael Büh/*

Page No. - Page No.

Design of a highly active $\mathrm{Pd}$

Catalyst with P,N Hemilabile Ligands for alkoxycarbonylation of alkynes and allenes: a density functional theory study 